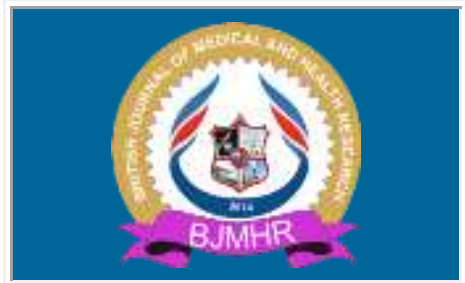

\title{
BJMHR
}

British Journal of Medical and Health Research Journal home page: www.bjmhr.com

\section{A Novel Approaches to Colon Targeted Drug Delivery System}

Mhetre RM*1, Gunale SB ${ }^{2}$, Holikatti SS ${ }^{\mathbf{1}}$, Kandale $\mathbf{J B}^{\mathbf{1}}$

1.Gandhi Natha Rangji College of D. Pharmacy, Solapur, Maharashtra, India. 2.Appasaheb Binale College of Pharmacy, Sangli, Maharashtra, India

\section{ABSTRACT}

The colon is a site where both local and systemic delivery of drugs can take place. Colonic drug delivery has gained increased importance not just for the delivery of the drugs for the treatment of local diseases associated with the colon like Crohn's disease, ulcerative colitis, etc. but also for the systemic delivery of proteins, therapeutic peptides, anti-asthmatic drugs, antihypertensive drugs and anti-diabetic agents. To achieve successful colon targeted drug delivery, a drug need to be protected from degradation, release and absorption in the upper portion of the GI tract and then to be ensured abrupt or controlled release in the proximal colon. This paper mainly compares the primary approaches for CDDS (Colon Specific Drug Delivery) namely prodrugs, $\mathrm{pH}$ and time dependent systems, and microbial triggered systems, which achieved limited success and had limitations as compared with newer CDDS namely pressure controlled colonic delivery capsules, CODESTM, and osmotic controlled drug delivery (ORDS-CT) which are unique in terms of achieving in vivo site specificity, and feasibility of manufacturing process. Treatment could be more effective if it is possible for drug to be directly delivered to colon.

Keywords: Novel, CDDS, Crohn's disease, ulcerative colitis. 


\section{INTRODUCTION}

Oral controlled - release formulations for the small intestine and colon have received considerable attention in the past 25 years for a variety of reasons including pharmaceutical superiority and clinical benefits derived from the drug - release pattern that are not achieved with traditional immediate (or) sustained - release products ${ }^{1}$.

By definition, colonic delivery refers to targeted delivery of drugs into the lower GI tract, which occurs primarily in the large intestine (i.e. colon). The site-specific delivery of drugs to lower parts of the GI tract is advantageous for localized treatment of several colonic diseases, mainly inflammatory bowel disease (Crohn's disease and ulcerative colitis), irritable bowel syndrome, and colon cancer. Other potential applications of colonic delivery include chronotherapy, prophylaxis of colon cancer and treatment of nicotine addiction. It has also gained increased importance not just for the delivery of drugs for the treatment of local diseases ${ }^{4}$, but also potential site for the systemic delivery of therapeutic proteins and peptides which are being delivered by injections. These delivery systems when taken orally, allow drugs to release the drug from the delivery system once the delivery system arrives into the colon.

These delayed mechanisms are designed to improve the efficacy of the drug by concentrating the drug molecules where they are need most, and also minimize the potential side effects and drug instability issues associated with premature release of drug in the upper parts of the GIT, namely stomach and small intestine.

Colon targeted drug delivery would ensures direct treatment at the disease site, lower dosing and less systemic side effects. In addition to restricted therapy, the colon can also be utilized as a portal for the entry of drugs into the systemic circulation. For example, molecules that are degraded/poorly absorbed in the upper gut, such as peptides and proteins, may be better absorbed from the more benign environment of the colon. . Overall, there is less free fluid in the colon than in the small intestine and hence, dissolution could be problematic for poorly water-soluble drugs. In such instances, the drug may need to be delivered in a pre-solubilized form, or delivery should be directed to the proximal colon, as a fluid gradient exists in the colon with more free water present in the proximal colon than in the distal colon. Aside from drug solubility, the stability of the drug in the colonic environment is a further factor that warrants attention. The drug could bind in a nonspecific manner to dietary residues, intestinal secretions, mucus or general faecal matter, thereby reducing the concentration of free drug. Moreover, the resident micro-flora could also affect colonic performance via degradation of the drug 4 .

\section{Why is colon targeted drug delivery needed?}

- Targeted drug delivery to the colon would ensure direct treatment at the disease site, lower dosing and fewer systemic side effects. 
- Site-specific or targeted drug delivery system would allow oral administration of peptide and protein drugs, colon-specific formulation could also be used to prolong the drug delivery.

- Colon-specific drug delivery system is considered to be beneficial in the treatment of colon diseases.

- The colon is a site where both local or systemic drug delivery could be achieved, topical treatment of inflammatory bowel disease, e.g. ulcerative colitis or Crohn's disease. Such inflammatory conditions are usually treated with glucocorticoids and sulphasalazine (targeted).

- A number of others serious diseases of the colon, e.g. colorectal cancer, might also be capable of being treated more effectively if drugs were targeted to the colon.

- Formulations for colonic delivery are also suitable for delivery of drugs which are polar and/or susceptible to chemical and enzymatic degradation in the upper GI tract, highly affected by hepatic metabolism, in particular, therapeutic proteins and peptides. ${ }^{4}$

\section{Advantages:}

- Oral delivery of drugs to the colon is valuable in the treatment of diseases of colon (ulcerative colitis, Chron's disease, carcinomas and infections)

- minimizing side effects that occur because of release of drugs in the upper GIT or unnecessary systemic absorption

- The colon is rich in lymphoid tissue, uptake of antigens into the mast cells of the colonic mucosa produces rapid local production of antibodies and this helps in efficient vaccine delivery

- The colon is attracting interest as a site where poorly absorbed drug molecule may have an improved bioavailability.

- This region of the colon is recognized as having a somewhat less hostile environment with less diversity and intensity of activity than the stomach and small intestine. ${ }^{4,5,6,}$

\section{Colon anatomy}

The GI tract is divided into stomach, small intestine and large intestine. The large intestine extending from the ileocecal junction to the anus is divided in to three main parts. These are the colon, the rectum and anal canal.

The entire colon is about 5 feet $(150 \mathrm{~cm})$ long, and is divided in to five major segments. Peritoneal folds called as mesentery which is supported by ascending and descending colon. The right colon consists of the cecum, ascending colon, hepatic flexure and the right half of the transverse colon and the values were shown in Table 1. The left colon contain the left half of 
the transverse colon, descending colon, splenic flexure and sigmoid. The rectum is the last anatomic segment before the anus. The human intestine and colon were shown in Figure 1 and Figure 2 respectively.

The major function of the colon is the creation of suitable environment for the growth of colonic microorganisms, storage reservoir of faecal contents, expulsion of the contents of the colon at an appropriate time and absorption of potassium and water from the lumen ${ }^{3}$. The absorptive capacity is very high, each about $2000 \mathrm{ml}$ of fluid enters the colon through the ileocecal valve from which more than $90 \%$ of the fluid is absorbed. On average, it has been estimated that colon contains only about 220 gm of wet material equivalent to just 35 gm of dry matter. The majority of this dry matter is bacteria. The colon tissue containing the villi, lymph, muscle, nerves, and vessels.

\section{Layers:}

- Serosa

- Muscularis externa

- Submucosa

- mucosa

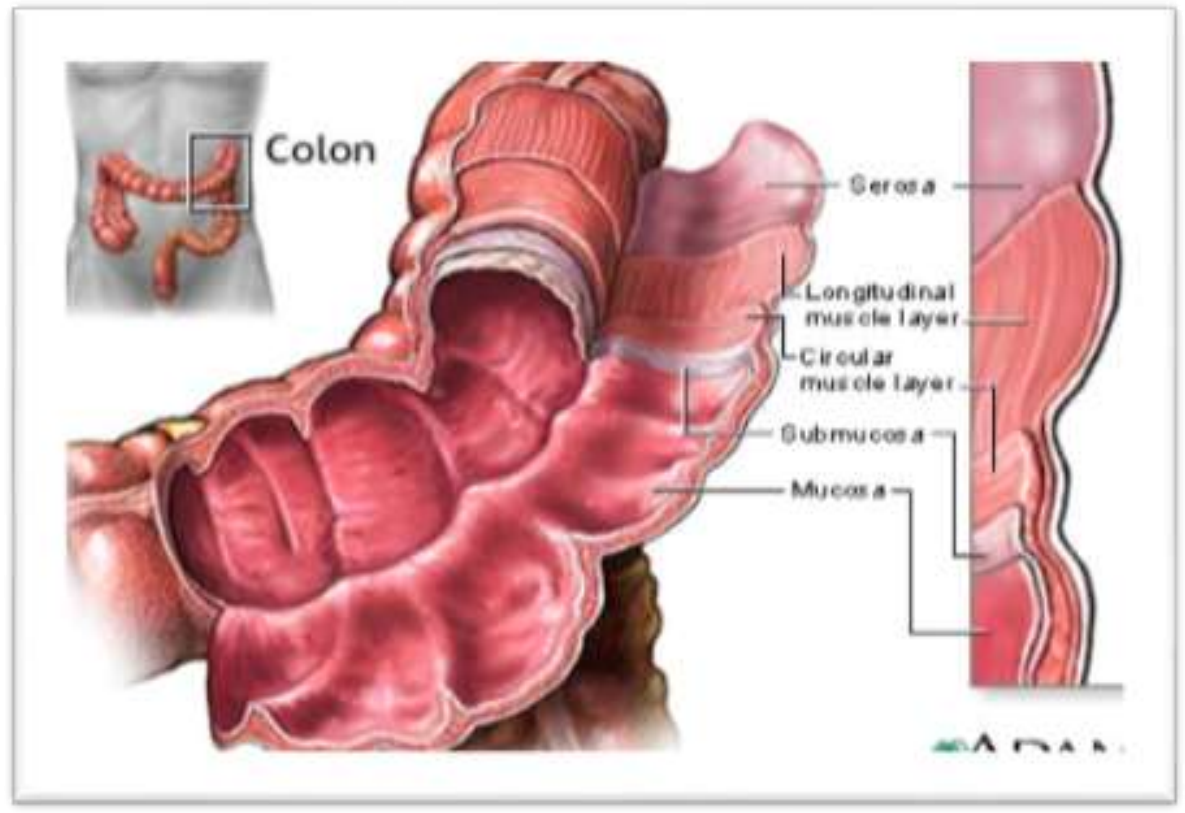

Figure 1: Layers of Colon 


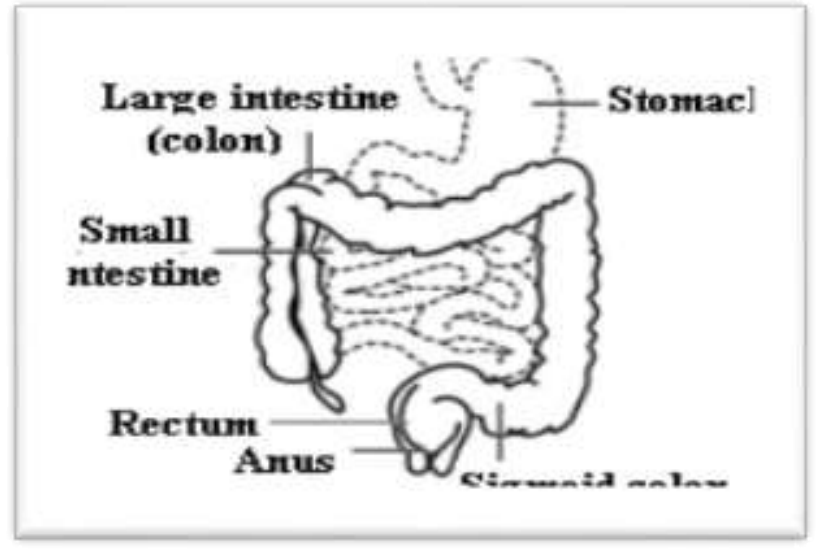

Figure 2: Structure of human intestine

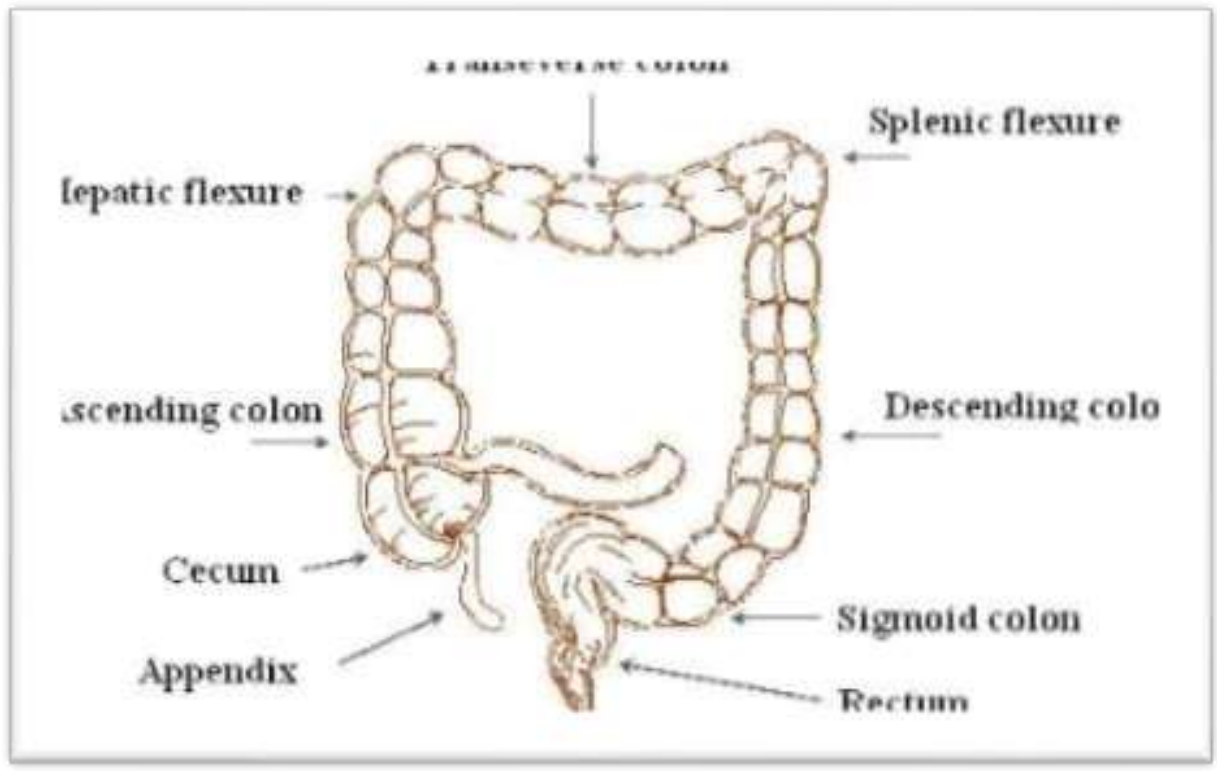

Figure 3: Structure of colon

Table 1: Measures of different parts of colon ${ }^{4,5,6}$

\begin{tabular}{lll}
\hline S.NO & Large Intestine & Length $(\mathbf{c m})$ \\
\hline 1 & Cecum & $6-9$ \\
2 & Ascending colon & $20-25$ \\
3 & Descending colon & $10-15$ \\
4 & Transverse colon & $40-45$ \\
5 & Sigmoid colon & $35-40$ \\
6 & Rectum & 12 \\
7 & Anal canal & 3 \\
\hline
\end{tabular}

\section{Drug absorption in the colon}

Drugs are absorbed passively by either paracellular or transcellular route. Transcellular absorption involves the passage of drugs through cells and this is the route most lipophilic drugs takes, where paracellular absorption involves the transport of drug through the tight junction between cells and is the route most hydrophilic drug takes.

The colon may not be the best site for drug absorption since the colonic mucosa lacks well defined villi as found in the small intestine. The slower rate if transit in colon lets the drug stay 
in contact mucosa for a longer period than in small intestine which compensates much lower surface area. The colon contents become more viscous with progressive absorption of water as one travels further through the colon. This causes a reduced dissolution rate, slow diffusion of drug through the mucosa. Theoretically, drug absorption can occur along the entire GI tract, while in actuality, most drugs are absorbed in the duodenum and proximal jejunum. Recent studies have shown that some drugs (e.g. Theophylline and Metoprolol) continue to be absorbed in the colon ${ }^{4,5,6}$

\section{Factors Affecting Absorption}

- * Physical properties of drug such as $\mathrm{pKa}$ and degree of ionization.

- Colonic residence time as commanded by GIT motility.

- Degradation by bacterial enzymes and metabolite products.

- Local physiological action of drug.

- Selective and non-selective binding to mucus.

- Disease state.

- Transit through GIT. $^{4}$

\section{Colonic microflora}

A large number of anaerobic and aerobic bacteria are present the entire length of the human GI tract. Over 400 distinct bacterial species have been found, 20-30\% of which are of the genus bacteroids $^{7}$. The upper region of the GIT has a very small number of bacteria and predominantly consists of gram positive facultative bacteria. The rate of microbial growth is greatest in the proximal areas because of high concentration of energy source.

The metabolic activity of microflora can be modified by various factors such as age, GI disease, and intake of drug and fermentation of dietary residues. ${ }^{4}$

\section{pH differences in the colon}

On entry in to the colon, the $\mathrm{pH}$ dropped to $6.4 \pm 0.5$. The $\mathrm{pH}$ in the mid colon was found to be $6.6 \pm 1$ and in the left colon, $7.0 \pm 1$ and the values are shown in Table 2 .

\section{Gastrointestinal transit}

Gastric emptying of dosage form is highly variable and depends primarily on whether the subject is fed or fasted and on the properties of the dosage form such as size and density. The transit times of dosage forms in tract are shown in Table 2.

\section{Table 2: Gastrointestinal Transit time of contents}

\begin{tabular}{ll}
\hline Organ & Transit Time (hr) \\
\hline Stomach & $<1$ (fasting) \\
Small intestine & $>3($ fed) \\
Large intestine & $3-4$ \\
& $20-30$ \\
\hline
\end{tabular}




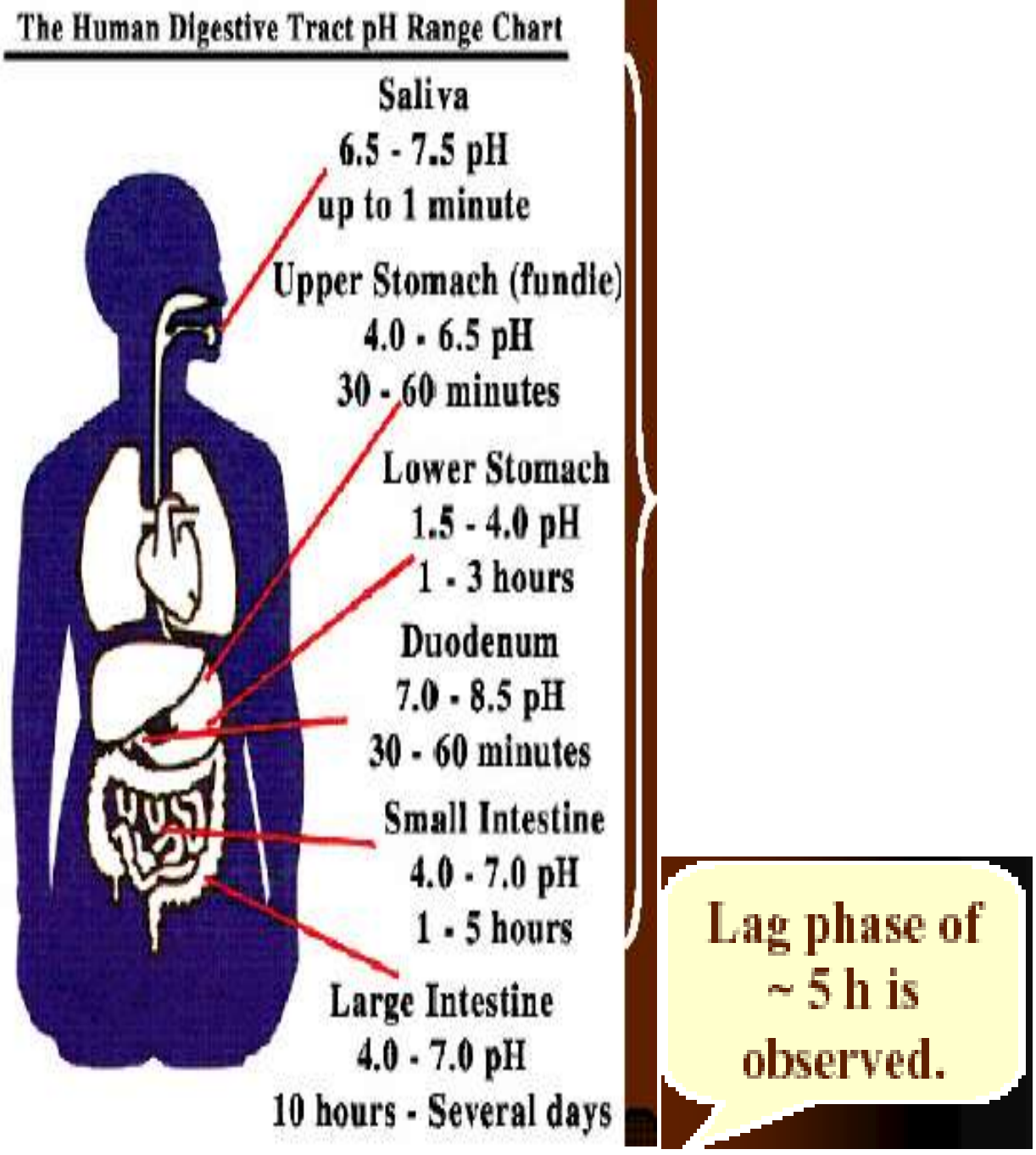

Figure 4: GIT pH range chart

Table 4: Average pH of the GI Tract ${ }^{4}$

\begin{tabular}{ll}
\hline Location & $\mathbf{p H}$ \\
\hline 1. Stomach & $1.5-2.0$ \\
Fasted condition & $3.0-5.0$ \\
Fed condition & $5.0-6.5$ \\
2. Small intestine & $6.0-7.5$ \\
Jejunum & 6.4 \\
Ileum & $6.7-7.3$ \\
3. Large intestine \\
Right colon \\
Mid colon and \\
Left colon \\
\hline
\end{tabular}

Diseases affecting colonic transit have important implications for drug delivery, diarrhea increases colonic transit and constipation decreases it. The digestive motility pattern takes place when food is present in the stomach. It is said by regular, frequent contractions (about 4-5/min.) which effect the mixing intestinal contents and moving them towards the colon in short segments and lasts as long as food remains present in the stomach. The most frequent 
movements seen in the colon are very slow segmenting movements that typically occurs every 30 minutes. ${ }^{4,5,6}$

\section{Oral preparations}

Solid formulations intended for targeted drug release into the lower gastrointestinal (GI) tract are beneficial for the localized treatment of several diseases and conditions, mainly inflammatory bowel diseases, irritable bowel syndrome and colon cancer. Also, because of their natural potential to delay or avoid systemic absorption of drug from the small intestine, colonic formulations can be utilized for chronotherapy of diseases which are affected by circadian biorhythms (e.g., asthma, hypertension and arthritis), and to achieve clinically significant bioavailability of drugs that are poorly absorbed from the upper parts of the gastrointestinal tract because of their polar nature and/or vulnerability to chemical and enzymatic degradation in the small intestine (e.g., peptides and proteins). The recent patent literature pertaining to various modified release (MR) formulation methods that are claimed to provide colonic delivery for a wide range of therapeutic agents. These technologies either utilize a single or a combination of two or more physiological characteristics of the colon, which includes $\mathrm{pH}$, microflora (enterobacteria), transit time, and luminal pressure. Accordingly, these technologies may be grouped under four distinct classes;

1. $\mathrm{pH}$-controlled (or delayed-release) system

2. Time-controlled (or time-dependent) system

3. Microbially-controlled system

4. Pressure-controlled system.

Among these, formulations that release drugs in response to colonic $\mathrm{pH}$, entero-bacteria, or both are most common and promising ${ }^{4,5}$

\section{Topical preparations}

Topical Preparations (foams, suppositories or enemas) plays major role in ulcerative colitis, either alone or in combination with oral steroids. They should generally not be used once a patient requires high-dose oral or intravenous steroid therapy.

\section{Old systemic and topical steroids}

Synthetic glucocorticoids such as prednisone, prednisolone, methyl-prednisolone, hydrocortisone, and ACTH are the most commonly used traditional corticosteroids in the treatment of ulcerative colitis. ${ }^{6,7}$

\section{Colonic diseases}

- Crohn's Diseases

- Ulcerative Colitis

- Diversional Colitis 
- Ischemic Colitis

- Diverticular Inflammatory Bowel Disease

- Colon Cancer

- Lymphoma of the Colon

\section{Inflammatory Bowel Disease}

The cause of inflammatory bowel disease is multi-factorials and it is due to the inflammatory responses, genetic factors such as multiple genetic factors, candidate genes, chromosome location, etc., infectious agents like Escherichia coli, Measles virus, Cytomegalovirus, etc., dietary factors such as saturated fats, milk products, allergic foods etc. It is a general term that has the following two diseases,

Ulcerative colitis

Crohn's disease

Ulcerative colitis occurs only in the large intestine. Ulcers form in the inner lining of the intestine, or mисоsa, of the colon or rectum, often resulting in diarrhea, blood, and pus. The inflammation is usually very rigorous in the sigmoid and rectum and usually reduces in the colon.

\section{What is ulcerative colitis?}

Ulcerative colitis is an inflammation of the lining of the large bowel (colon and rectum). Symptoms include rectal bleeding, diarrhea, abdominal cramps, weight loss, and fevers. In addition, patients who have had extensive ulcerative colitis for many years are at an increased risk to develop large bowel cancer. The cause of ulcerative colitis remains unknown. ${ }^{4}$

\section{How is ulcerative colitis treated?}

Initial treatment of ulcerative colitis is medical, using antibiotics and anti-inflammatory medications such as aminosalicylates. If these fail, prednisone can be used for a short period of time but long-term use can be associated with

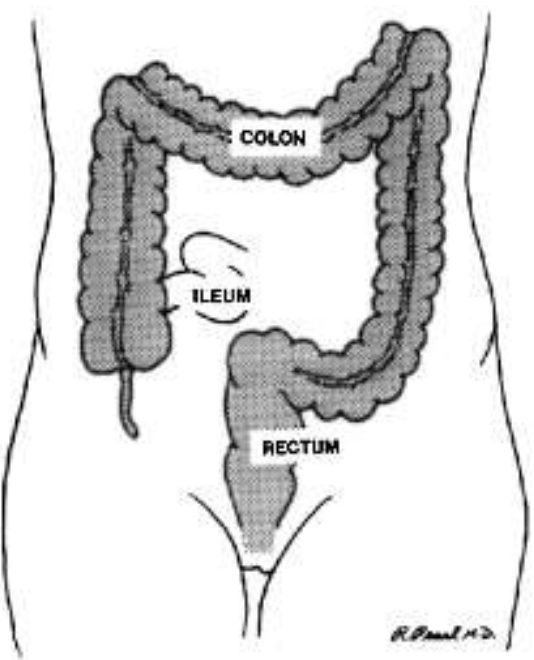
significant side effects. If prednisone is ineffective or cannot be discontinued, immunomodulators such as 6-mercaptopurine or azathioprine can be used to control active disease that does not merit hospitalization. In order to maintain control of the disease, aminosalicylates or immunomodulators are used on a long-term basis. "Flare-ups" of the disease can often be treated by increasing the dosage of medications or adding new medications. Hospitalization may be necessary to put the bowel to rest and deliver steroids directly into the blood stream. 


\section{When is surgery necessary?}

Surgery is indicated for patients who have life-threatening complications of inflammatory bowel diseases, such as massive bleeding, perforation, or infection. It may also be necessary for those who have the chronic form of the disease, which fails to improve with medical therapy. It is important the patient be comfortable that all reasonable medical therapy has been attempted prior to considering surgical therapy. In addition, patients who have long-standing ulcerative colitis may be candidates for removal of the large bowel, because of the increased risk of developing cancer. More often, these patients are followed carefully with repeated colonoscopy and biopsy, and surgery is recommended only if precancerous signs are identified.

\section{Crohn's disease:}

Crohn's disease, also called regional enteritis, is a chronic inflammation of the intestines which is usually confined to the terminal portion of the small intestine, the ileum. Ulcerative colitis is a common inflammation of the colon, or large intestine. These diseases and other inflammatory bowel disease have been linked with an increased risk of colorectal cancer.

\section{What is Crohn's disease?}

Crohn's disease is a chronic inflammatory process primarily involving the intestinal tract. Although it may involve any part of the digestive tract from the mouth to the anus, it most commonly affects the last part of the small intestine (ileum) and/or the large intestine (colon and rectum).

Crohn's disease is a chronic condition and may recur at various times over a lifetime. Some people have long periods of remission, sometimes for years, when they are free of symptoms. There is no way to predict when a remission may occur or when symptoms will return.

\section{What are the symptoms of Crohn's disease?}

Because Crohn's disease can affect any parte intestine, symptoms may vary greatly from patient to patient. Common symptoms include cramping, abdominal pain, diarrhea, fever, weight loss, and bloating. Not all

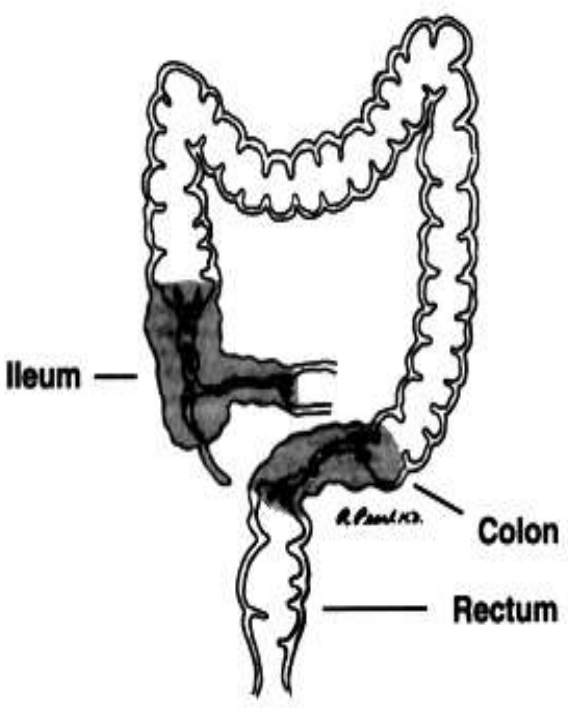
patients experience all of these symptoms, and some may experience none of them. Other symptoms may include anal pain or drainage, skin lesions, rectal abscess, fissure, and joint pain (arthritis). ${ }^{4}$

\section{Common Crohn's symptoms: ${ }^{4}$}

- Cramping - abdominal pain

- Diarrhea 
- Fever

- Weight loss

- Bloating

- Anal pain or drainage

- Skin lesions

- Rectal abscess

- Fissure

- Joint pain

\section{Who does it affect?}

Any age group may be affected, but the majority of patients are young adults between 16 and 40 years old. Crohn's disease occurs most commonly in people living in northern climates. It affects men and women equally and appears to be common in some families. About 20 percent of people with Crohn's disease have a relative, most often a brother or sister, and sometimes a parent or child, with some form of inflammatory bowel disease.

\section{Diagnosis of inflammatory bowel disease $\mathrm{e}^{4,12,13}$}

Blood tests: An increased number of white blood cells may indicate the presence of inflammation. New blood tests that measure certain antibodies may make it easier to differentiate Crohn's disease from ulcerative colitis. Feces sample is also taken and examined for blood, infectious agents, or both.

Endoscopic technique: Flexible sigmoidoscopy and colonoscopy are endoscopic techniques. They are important in the diagnosis of both ulcerative colitis and Crohn's disease and both techniques involve snaking a fiber optic tube called an endoscope through the rectum to view the lining of the colon. The tissue sample may also be collected for a biopsy.

The other diagnostic techniques of this disease are constellation of positive endoscopic, ratiographic, and histological findings with negative stool cultures. The differential diagnosis of IBS includes infectious colitis, celiac sprue, intestinal lymphoma, radiation enteropathy, NSAIDs use, and ischemic colitis.

\section{Approaches to colon-specific drug delivery}

Colon-specific drug delivery is considered beneficial in the treatment of colon-related diseases and the oral delivery of protein and peptide drugs. Generally, each colon-specific drug delivery system has been designed based on one of the following mechanisms with varying degrees of success;

1. Coating with $\mathrm{pH}$ dependent polymers

2. Coating with pH independent biodegradable polymers

3. Delivery systems based on the metabolic activity of colonic bacteria 


\section{Prodrugs}

\section{Hydrogels}

\section{Polysaccharides}

Formulations for colonic delivery are also suitable for delivery of drugs which are polar and/or susceptible to chemical and enzymatic degradation in the upper GI tract, in particular, therapeutic proteins and peptides. Proteins and peptides such as insulin, calcitonin and vasopressin may be delivered systemically via colonic absorption. Other examples include novel peptides such as cytokine inhibitors and antibiotics, which are useful in the treatment of inflammatory bowel diseases and GI infections, respectively. Apart from protecting these labile molecules, colon also offers an opportunistic site for oral delivery of vaccines because it is rich in lymphoid tissue. Therefore, the uptake of antigens through the colonic mucosa may lead to rapid and local production of antibodies. There is also an increasing interest in the colonic delivery for improving the oral bioavailability of drugs that are substrates of metabolizing enzymes is comparatively lower in the colonic mucosa than in the small intestine. Increasing bioavailability via a colonic formulation approach has also been found to be effective in minimizing unwanted side-effects. Drug release from this system is triggered by colonic microflora coupled with $\mathrm{pH}$ sensitive polymer coating ${ }^{10,11}$

\section{Coating with pH dependent polymers}

In these systems drugs can be formulated as solid dosage forms such as tablets, capsules and pellets and coated with $\mathrm{pH}$ sensitive polymers as an enteric coating. Widely used polymers are methacrylic resins (Eudragit) which are available in water soluble and insoluble forms. Eudragit L and S are copolymers of methacrylic acid and methacrylate. 5-aminosalicylic acid is commercially available as an oral dosage form coated with Eudragit L and S. Other colonspecific delivery systems based on methacrylic resins are described for prednisolone, insulin and quinolones.

The $\mathrm{pH}$-dependent systems exploit the generally accepted view that $\mathrm{pH}$ of the human GIT increases progressively from the stomach ( $\mathrm{pH}$ 1-2 which increase to 4 during digestion), small intestine ( $\mathrm{pH} 6$ - 7) at the site of digestion and it increases to 7-8 in the distal ileum. The gamma scintigraphy technique becomes most popular technique to investigate the gastrointestinal performance of pharmaceutical formulations.

Mostly used polymer most commonly used $\mathrm{pH}$-dependent coating polymers are methacrylic acid copolymers, commonly known as Eudragit S more specifically Eudragit L and S. Eudragit L100 and S100 are the copolymers of methacrylic acid and methyl methacrylate. Carboxyl polymer form salts and dissolve above $\mathrm{pH} 5.5$ and disperse in water to form latex and thus avoid the use of organic solvents is the coating process. Eudragit L100-55 polymers with 
ionizable phthalic acid groups dissolve much faster and at a lower $\mathrm{pH}$ than those with acrylic or methacrylic acid groups.

Colon targeted drug delivery systems based on methycrylic resins has described for insulin, prednisolone, quinolones, salsalazine, cyclosporine, beclomethasone dipropionate and naproxane, Khan et al. prepared lactose-based placebo tablets and coated using various combinations of two methacrylic acid polymers, Eudragit L100-55 and Eudragit 100 by spraying from aqueous systems. The same coating formulations are then applied on tablets and evaluated for in vitro dissolution rates under various conditions. Dissolution studies performed on the mesalazine tablets further confirmed that the release profiles of the drug could be manipulated by changing the Eudragit L100-55 and Eudragit S100 ratios within the $\mathrm{pH}$ range of 5.5 to 7.0 in which the individual polymers are soluble respectively, and a coating formulation consisting of a combination of the two copolymers can overcome the issue of high GI pH variability among individuals. Enteric polymers used for such modified release dosage form is summarized in Table $6,7 \cdot 14$

Table 5: Enteric Polymers Used for Such Modified Release Dosage Form ${ }^{14}$

\begin{tabular}{|c|c|}
\hline Polymer & Threshold pH \\
\hline Eudragit $^{10} \mathrm{~L} 100$ & 6.0 \\
\hline Eudragit ${ }^{\circ} \mathrm{S} 100$ & 7.0 \\
\hline Eudragit $^{*} \mathrm{~L}-30 \mathrm{D}$ & 5.6 \\
\hline Eudragit $^{10}$ FS 30D & 6.8 \\
\hline Eudragit ${ }^{10}$ L 100-55 & 5.5 \\
\hline Polyvinyl acetate phthalate & 5.0 \\
\hline Hydroxy propyl methyl cellulose phthalate & $4.5-4.8$ \\
\hline Hydroxy propyl methyl cellulose phthalate 50 & 5.2 \\
\hline HPMC 55 & 5.4 \\
\hline Cellulose acetate trimelliate & 4.8 \\
\hline Cellulose acetate phthalate & 5.0 \\
\hline
\end{tabular}

\section{Coating with $\mathrm{pH}$ independent biodegradable polymers ${ }^{13,14}$}

Drugs that are coated with the polymers, which are showing degradability due to the influence of colonic microorganisms, can be exploited in designing drugs for colon targeting in order to release an orally administered drug in the colon.

The intestinal microflora has a large metabolic capacity and it appears that reduction of azo bonds is a general reaction of colonic bacteria. The azo polymers having a high degree of hydrophilicity were degraded by colonic bacteria.

The copolymers of styrene and 2-hydroxy methyl methacrylate which were cross linked with divinyl azo benzene and N.N ${ }^{1}$ bis ( $\beta$-styrene sulphonyl) - 4, $4^{1}$-diamino azo- benzene to coat 
oral dosage forms of insulin and vasopressin. On arrival at the colon the coating is degraded by bacterial azo reductases there by releasing the drug.

\section{Delivery systems based on the metabolic activity of colonic bacteria}

\section{Prodrugs 10,11}

Prodrugs $^{8}$ of steroids having a hydroxyl group at C-21 position were prepared using poly-1aspartic acid carrier. The ester prodrug of dexamethasone with poly-1-aspartic acid when subjected to in vitro drug release studies in gastro intestinal tract homgenates released dexamethasone because of the cleavage of the ester bond by bacterial enzymes.

The polymeric prodrugs of sulfasaslazine, is used in the treatment of ulcerative colitis and crohn's disease. Chemically sulfasaslazine is 5- aminosalicylic acid (5-ASA) coupled with sulphapyridine by azo bonding. On arrival at the colon the azo bond is reduced by colonic azo reductases to 5-ASA and sulphapyridne ${ }^{17,18}$.

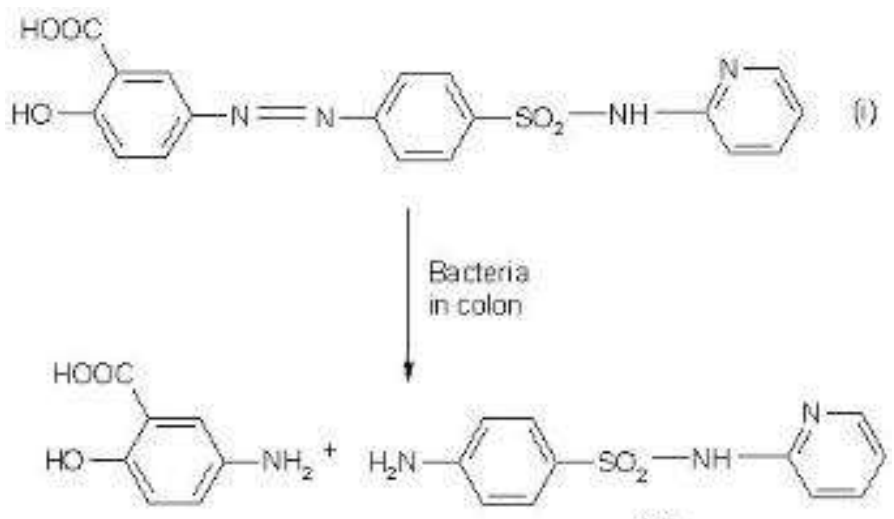

(ii)

(iii)

Hydrolysis of sulfasalazine (i) into 5-aminosalicylic acid (ii) and sulfapyridine

Classical prodrug design often represents a nonspecific chemical approach to mask unwanted drug properties such as low bioavailability, less site specificity, and chemical instability. On the other hand, targeted prodrug design represents a new strategy for directed and efficient drug delivery. Particularly, prodrugs targeting to a specific enzyme or a specific membrane transporter, or both, have potential drug delivery system especially for cancer chemotherapy. Site specific targeting with prodrugs can be further improved by the simultaneous use of gene delivery to express the requisite enzymes or transporters. This review highlights evolving strategies in targeted prodrug design, including antibody directed enzyme prodrug therapy, gene directed enzyme prodrug therapy, and peptide transporter-associated prodrug therapy.

\section{Strategy for pro-drug site-specific drug delivery}

The use of prodrugs has been actively pursued to achieve very precise and direct effects at the "site of action," with minimal effect on the rest of the body. There are at least three factors should be optimized for the site specific delivery of drugs by using the prodrug approach 
1. The prodrug must to reach the target for the site of action as early as possible, and uptake from the site must be fast and essentially perfusion rate limited.

2. Once the drug reached to the site, prodrug must be selectively liberated to the active drug relative to its conversion at other sites.

3. Once selectively liberated at the site of action, the active drug must be somewhat retained by the tissue. ${ }^{10,11}$

\section{Targeted Prodrug Design}

Prodrugs can be designed to target specific enzymes or carriers by considering enzyme substrate specificity or carrier substrate specificity in order to overcome various unwanted drug properties. This type of targeted prodrug design requires considerable knowledge related to a particular enzymes or carrier systems including their molecular and functional characteristics. Targeted prodrug design discussed in 2 categories:

1. Targeting specific enzymes and

2. Targeting specific membrane transporters. ${ }^{10,11}$

\section{Prodrug Design Targeting Enzymes}

In prodrug design, enzymes can be recognized as pre-systemic metabolic sites and an irreversible chemical modification technique is more successfully achieved to reduce the presystemic metabolism by targeting enzymes rather than by a prodrug approach. The enzyme targeted prodrug approach can be widely used to improve oral drug absorption, as well as site specific drug delivery. In the case of enhancing oral drug absorption, GI enzymes may be the main targets for prodrug design, and the use of a nutrient moiety as a derivatizing group permits more specific targeting for gastro-intestinal enzymes to improve oral drug absorption. These prodrugs have the further advantage of producing nontoxic nutrient byproducts when they regenerate the active drugs in-vivo. Extensive studies on gastrointestinal enzymes, which provide necessary information (e.g., enzyme distribution, activity, and specificity) for prodrug design.

In the prodrug approach, site specific delivery can be obtained from tissue specific activation of a prodrug, which is the result of metabolism by an enzyme that is either exceptional for the tissue or present at a higher amount (compared with other tissues); thus, it activates the prodrug more competently. For example, glycosidase activity of the colonic microflora offers an opportunity to design a colon specific drug delivery system. Glycoside derivatives are hydrophilic and are poorly absorbed from the small intestine, but once they reach the colon, they can be effectively liberated by bacterial glycosidase to release the free drug and facilitates the absorption by the colonic mucosa. These glycosidic prodrugs, the dexamethasone glucoside appeared to be the better candidate, with nearly $60 \%$ of the orally administered prodrugs 
reaching the caecum as a free steroid, while orally administered parent steroids were absorbed almost from the small intestine. L-dopa was decarboxylated to dopamine by aromatic L-amino acid decarboxylase, which is highly concentrated in the kidney. The concentration of dopamine in the kidney after administration of L-- glutamyl dopa was almost 5 times higher than that after an equivalent dose of L-dopa. Appropriately designed prodrugs have been found to be effective in the treatment of animal tumors possessing high levels of an activating enzyme. However, clinical results were unsatisfactory when it was found that the human tumors containing appropriately high levels of the activating enzymes were rare and that the high levels of activating enzymes were not associated with any particular type of tumor. Recently, new therapies have been proposed to overcome this limitation of prodrug therapy. ${ }^{10,11}$

These new approaches are referred to as;

- ADEPT (antibody-directed enzyme prodrug therapy - shown in Figure 5), and

- GDEPT (gene-directed enzyme prodrug therapy - shown in Figure 6, which attempt the localization of prodrug activation enzymes into specific cancer cells prior to prodrug administration.

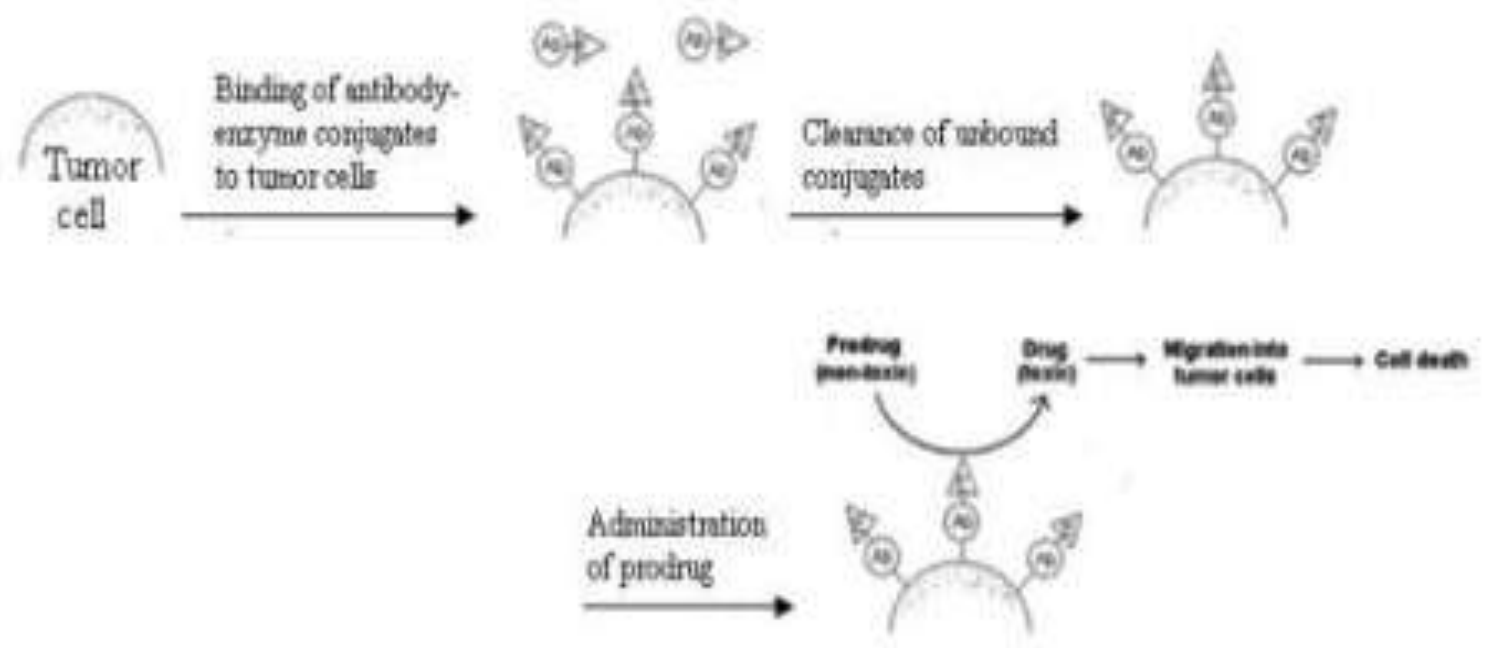

Figure 5. Schematic representation of ADEPT. 


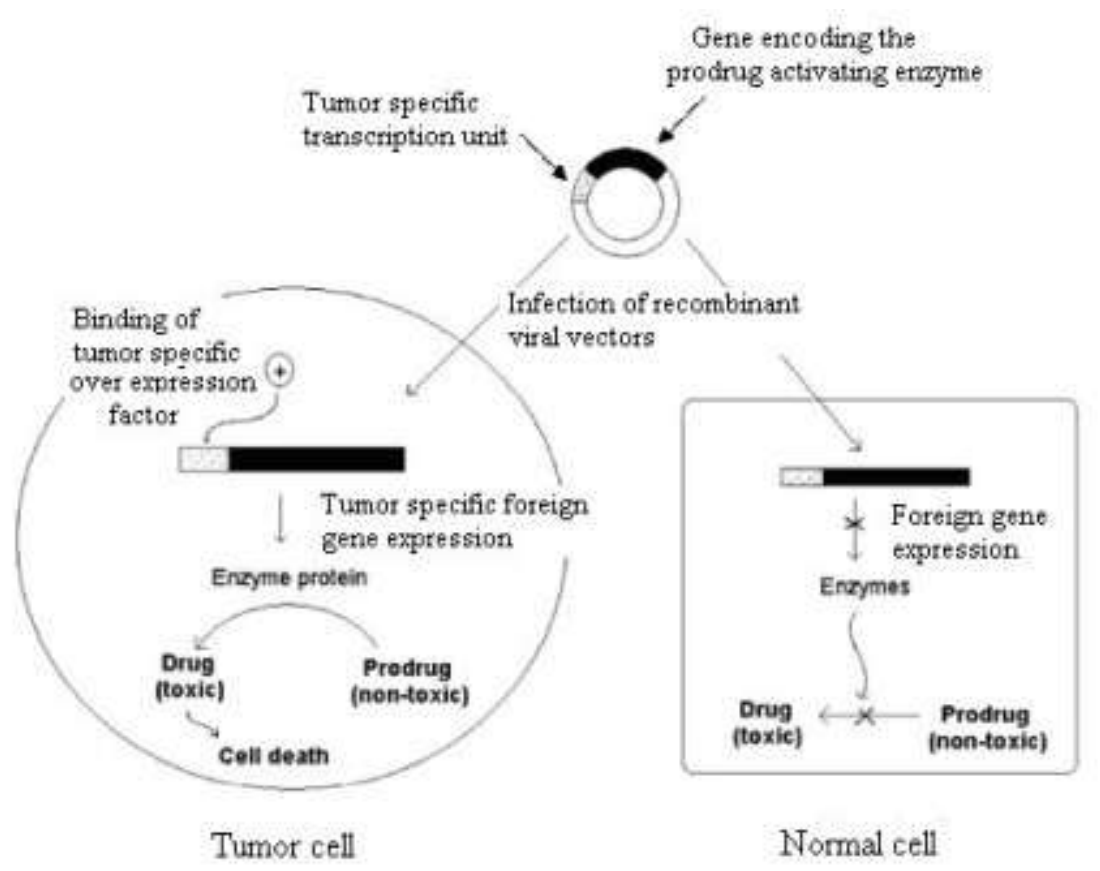

Figure 6. Schematic representation of GDEPT.

\section{Hydrogels}

The Hydrogels contain acidic co-monomers and enzymatically degradable azoaromatic crosslinks. In the acidic $\mathrm{pH}$ of stomach, the gels have a low degree of swelling, which protect the drug against degradation by digestive enzymes. As the gels pass down the GI tract, the degree of swelling increases. On entering the colon, the gels reach a degree of swelling making the cross-links accessible to enzymes (azoreductases) or mediators (electron carriers).

A number of drug delivery devices have been proposed to deliver the drug for efficient therapy. Among them, Hydrogels, specially based on polysaccharides, have attracted considerable attention as an excellent candidates for controlled release devices or targetable devices of the therapeutic agents. The release rate of drugs from hydrogels was primarily determined by the swelling extent, which further enhanced by addition of enzyme in the buffer solutions whereas swelling of polymeric networks was depended on composition of copolymer and $\mathrm{pH}$ of the surrounding medium. The controlled release of active anti-microbial agents- amoxicillin, metronidazole, oxytetracycline and tetracycline- $\mathrm{HCl}$ from the polymeric matrix have been well reported.

Diffusion mechanism of the drugs from the polymeric matrix can be calculated from the equation; 


$$
\begin{aligned}
& \frac{\mathrm{M}_{\mathrm{t}}}{\mathrm{M}_{\infty}}=\mathrm{kt}^{\mathrm{n}} \\
& \frac{\mathrm{M}_{\mathrm{t}}}{\mathrm{M}_{\infty}}=4\left(\frac{\mathrm{Dt}}{\pi \lambda^{2}}\right)^{0.5} \\
& D_{A}=\frac{0.049 \lambda^{2}}{t^{1 / 2}} \\
& \frac{\mathrm{M}_{\mathbf{t}}}{\mathrm{M}_{\infty}}=\mathbf{1}-\left(\frac{8}{\pi^{2}}\right) \exp \left[\frac{\left(-\pi^{2} \mathrm{D}_{\mathrm{t}}\right)}{\lambda^{2}}\right] \rightarrow(4)
\end{aligned}
$$

Where;

$\mathrm{Mt} / \mathrm{M} \infty$ is the fractional release of drug in time $t$, ' $k$ ' is the constant characteristic of the drugpolymer system, and ' $n$ ' is the diffusion exponent ' $D$ ' is the diffusion coefficient and ' $\lambda$ ' is the thickness of the sample.

The release of water-soluble drugs, entrapped in a hydrogels, occur only after water penetrates the polymeric networks to swell and dissolve the drug, followed by diffusion along the aqueous pathways to the surface of the device. The release of drug is closely related to the swelling characteristics of the hydrogels, which in turn, is a, key function of chemical architecture of the hydrogels. In the present study the effect of $\mathrm{pH}$ on the release pattern of tetracycline have been studied by varying the $\mathrm{pH}$ of the release medium. The amount of drug release in $\mathrm{pH} 7.4$ buffer was higher than the release medium of $\mathrm{pH} 2.2$ buffer and distilled water. The swelling of hydrogels [psy-clpoly(AAm)], increased when the $\mathrm{pH}$ of the medium changed from acidic to basic. At lower $\mathrm{pH}$ values the $-\mathrm{CONH} 2$ groups does not ionized and keep the polymeric networks at its collapsed state. At high $\mathrm{pH}$ values, it is partially ionize $\mathrm{d}$, and the charged COO groups repel each other, leading to the higher swelling of the polymer and resultant to more drug release. The release of drug was observed to be faster in $\mathrm{pH} 7.4$ (Equation 1). From the percent cumulative release studies of tetracycline it was observed that first $50 \%$ of the total release occurred in 90min., 120min. and 135min. in releasing medium of $\mathrm{pH} 7.4$ buffer, $\mathrm{pH} 2.2$ buffer and distilled water respectively. The diffusion exponent ' $\mathrm{n}$ ' have $0.74,0.60$ and 0.56 values and gel characteristic constant ' $\mathrm{k}$ ' have $1.272 \times 10-2,2.754 \times 10-2$ and 3.639×10-2 values in distilled water, $\mathrm{pH} 2.2$ buffer and $\mathrm{pH} 7.4$ buffer respectively for the tetracycline release from the hydrogels and these values were obtained from the slope and intercept of the plot between 
in $\mathrm{Mt} / \mathrm{M} \infty$ versus $\ln \mathrm{t}$ (Equation 2). It means Non-Fickian or Anomalous diffusion occurs for the tetracycline release from the Hydrogels. It is also observed that in each release medium the Initial diffusion coefficient was observed to more than late time diffusion coefficient. ${ }^{11,12,13,14}$

\section{Polysaccharides as carriers}

Natural polysaccharides such as pectin and xylan are not digested in human stomach or small intestine, but are degraded in the colon by resident bacteria. Pectin in the form of compression coat was evaluated for targeting to colon. The coat was susceptible to enzymatic attack in the colon there by releasing the drug.

A novel tablet formulation for oral administration using guar gum as a carrier and indomethacin, metronidazole, Albendazole, Mebendazole as a model drug. Drug release studies under conditions mimicking mouth to colon transit have shown the guar gum protects the drug from being released completely in the physiological environment of stomach and small intestine.

Inulin is the other natural polysaccharide found in many plants such as onion, garlic. Inulin HP (High degree of polymerization) incorporated in Eudragit RS film was evaluated as a possible biodegradable coating for colonic drug delivery. Polymers that undergo Microbially degradation and used for colonic drug delivery are summarized in Table 5.

\section{General considerations for design of colonic formulations}

Formulations for colonic delivery are, in general, delayed-released dosage forms which maybe designed either to provide a 'burst release' or a sustained / prolonged / targeted.

a. Pathology and of disease, especially the affected parts of the lower GIT.

b. Physicochemical and biopharmaceutical properties of the drug such as solubility, stability and permeability at the intended site of delivery.

c. The preferred release data of the drug.

Very common physiological factor which is considered in the design of delayed release colonic formulations is $\mathrm{pH}$ gradient of the GI tract. In normal healthy subjects, there is a progressive increase in luminal $\mathrm{pH}$ from the duodenum $(\mathrm{pH}$ is $6.6 \pm 0.5)$ to the end of the ileum $(\mathrm{pH}$ is $7.5 \pm$ 0.4 ), a decrease in the cecum ( $\mathrm{pH}$ is $6.4 \pm 0.4$ ), and then a slow rise from the right to the left colon with a final value of $7.0 \pm 0.7$. Some reports suggested that alterations in gastrointestinal $\mathrm{pH}$ profiles may occur in patients with inflammatory bowel disease, which should be considered in the development of delayed release formulations.

\section{Types or modified release formulations for colon targeted drug delivery systems} These are of two types:

Single unit colon targeted drug delivery system: It may suffer from the disadvantage of unintentional disintegration of the formulation due to manufacturing deficiency or unusual 
gastric physiology that may lead to drastically compromised systemic drug bioavailability or loss of local therapeutic action in the colon.

\section{Multiparticulate dosage form systems:}

These are developed in comparison to single unit systems because of their potential benefits like increased bioavailability, reduced risk of systemic toxicity, reduced risk of local irritation and predictable gastric emptying. Multiparticulate approaches tried for colonic delivery includes formulations in the form of pellets, granules, microparticles and nanoparticles. The use of multiparticulate formulations in preference to single unit dosage forms for colon targeting purposes. Showed that multiparticulate formulations enabled the drug to reach the colon quickly and were retained in the ascending colon for a relatively long period of time. Because of their smaller particle size as compared to single unit dosage forms these systems tend to be more uniformly dispersed in the GI tract and also ensure more uniform drug absorption. Most commonly investigated multiparticulate formulations for colon specific drug delivery include pellets, granular matrices, beads, microspheres, and nanoparticles.

\section{. Limitations and challenges in colon targeted drug delivery}

- One challenge in the development of colon-specific drug delivery systems is to establish an appropriate dissolution testing method to evaluate the designed system invitro. This is due to the rationale after a colon specific drug delivery system is quite diverse.

- As a site for drug delivery, the colon offers a near neutral $\mathrm{pH}$, reduced digestive enzymatic activity, a long transit time and increased responsiveness to absorption enhancers; however, the targeting of drugs to the colon is very complicated. Due to its location in the distal part of the alimentary canal, the colon is particularly difficult to access. In addition to that the wide range of $\mathrm{pH}$ values and different enzymes present throughout the gastrointestinal tract, through which the dosage form has to travel before reaching the target site, further complicate the reliability and delivery efficiency.

- Successful delivery through this site also requires the drug to be in solution form before it arrives in the colon or, alternatively, it should dissolve in the luminal fluids of the colon, but this can be a limiting factor for poorly soluble drugs as the fluid content in the colon is much lower and it is more viscous than in the upper part of the GI tract.

- In addition, the stability of the drug is also a concern and must be taken into consideration while designing the delivery system. The drug may potentially bind in a nonspecific way to dietary residues, intestinal secretions, mucus or faecal matter.

- The resident microflora could also affect colonic performance via metabolic degradation of the drug. Lower surface area and relative 'tightness' of the tight 
junctions in the colon can also restrict drug transport across the mucosa and into the systemic circulation.

- The literature also suggested that the cytochrome P-450(3A) class of drug metabolizing enzymes have lower activity in the colonic mucosa. A longer residence time of 3 to 5 days results in elevated plasma levels of the drugs and therefore higher bioavailability in general, but especially for drugs that are substrates for this class of enzyme.

\section{Current and future developments}

Currently, there are several modified release solid formulation technologies available for colonic delivery. These technologies rely on GI pH, transit times, enterobacteria and luminal pressure for site-specific delivery. Each of these technologies represents a unique system in terms of design but has certain shortcomings, which are often related to degree of sitespecificity, toxicity, cost and ease of scale up/manufacturing. It appears that microbiallycontrolled systems based on natural polymers have the greatest potential for colonic delivery, particularly in terms of site-specificity and safety. In this regard, formulations that employ a film coating system based on the combination of a polysaccharide and a suitable film forming polymer represents a significant technological advancement. Further developments in this area require means to improve the co-processing of the polymeric blend of a polysaccharide(s) and a film forming material while maintaining the propensity of the composition to microbial degradation in the colon.

\section{Novel Drug Delivery Systems for CDDS}

Now a day the basic CDDS approaches are applied to formulate novel drug delivery systems like Multiparticulate systems, Microspheres, Liposomes, Microencapsulated particles etc.

\section{Primary Approaches for CDDS}

\section{pH Sensitive Polymer Coated Drug Delivery to the Colon}

In the stomach, $\mathrm{pH}$ ranges between 1 and 2 during fasting but increases after eating. 21 The $\mathrm{pH}$ is about 6.5 in the proximal small intestine, and about 7.5 in the distal small intestine.22 From the ileum to the colon, $\mathrm{pH}$ declines significantly. It is about 6.4 in the cecum. However, $\mathrm{pH}$ values as low as 5.7 have been measured in the ascending colon in healthy volunteers. ${ }^{23}$ The $\mathrm{pH}$ in the transverse colon is 6.6 and 7.0 in the descending colon. Use of $\mathrm{pH}$ dependent polymers is based on these differences in $\mathrm{pH}$ levels. The polymers described as $\mathrm{pH}$ dependent in colon specific drug delivery are insoluble at low $\mathrm{pH}$ levels but become increasingly soluble as $\mathrm{pH}$ rises.24 Although a $\mathrm{pH}$ dependent polymer can protect a formulation in the stomach, and proximal small intestine, it may start to dissolve in the lower small intestine, and the sitespecificity of formulations can be poor.25 The decline in $\mathrm{pH}$ from the end of the small intestine to the colon can also result in problems, lengthy lag times at the ileo-cecal junction or rapid 
transit through the ascending colon which can also result in poor site-specificity of entericcoated single-unit formulations.

\section{Delayed (Time Controlled Release System) Release Drug Delivery to Colon}

Time controlled release system (TCRS) such as sustained or delayed release dosage forms are also very promising drug release systems. However, due to potentially large variations of gastric emptying time of dosage forms in humans, in these approaches, colon arrival time of dosage forms cannot be accurately predicted, resulting in poor colonical availability.26 The dosage forms may also be applicable as colon targeting dosage forms by prolonging the lag time of about 5 to $6 \mathrm{~h}$. However, the disadvantages of this system are:

i. Gastric emptying time varies markedly between subjects or in a manner dependent on type and amount of food intake.

ii. Gastrointestinal movement, especially peristalsis or contraction in the stomach would result in change in gastrointestinal transit of the drug. ${ }^{27}$

iii. Accelerated transit through different regions of the colon has been observed in patients with the IBD, the carcinoid syndrome and diarrhea, and the ulcerative colitis. ${ }^{9,28,29}$

Therefore, time dependent systems are not ideal to deliver drugs to the colon specifically for the treatment of colon related diseases. Appropriate integration of $\mathrm{pH}$ sensitive and time release functions into a single dosage form may improve the site specificity of drug delivery to the colon. Since the transit time of dosage forms in the small intestine is less variable i.e. about $3 \pm 1 \mathrm{hr} .30$ The time-release function (or timer function) should work more efficiently in the small intestine as compared the stomach. In the small intestine drug carrier will be delivered to the target side, and drug release will begin at a predetermined time point after gastric emptying. On the other hand, in the stomach, the drug release should be suppressed by a $\mathrm{pH}$ sensing function (acid resistance) in the dosage form, which would reduce variation in gastric residence time.27 Enteric coated time-release press coated (ETP) tablets, are composed of three components, a drug containing core tablet (rapid release function), the press coated swellable hydrophobic polymer layer (Hydroxy propyl cellulose layer (HPC), time release function) and an enteric coating layer (acid resistance function).26,31 The tablet does not release the drug in the stomach due to the acid resistance of the outer enteric coating layer. After gastric emptying, the enteric coating layer rapidly dissolves and the intestinal fluid begins to slowly erode the press coated polymer(HPC) layer. When the erosion front reaches the core tablet, rapid drug release occurs since the erosion process takes a long time as there is no drug release period (lag phase) after gastric emptying. The duration of lag phase is controlled either by the weight or composition of the polymer (HPC) layer.

\section{Microbially Triggered Drug Delivery to Colon}


The microflora of the colon is in the range of $1011-1012 \mathrm{CFU} / \mathrm{mL}$, consisting mainly of anaerobic bacteria, e.g. bacteroides, bifidobacteria, eubacteria, clostridia, enterococci, enterobacteria and ruminococcus etc. 28 This vast microflora fulfills its energy needs by fermenting various types of substrates that have been left undigested in the small intestine, e.g. di- and tri-saccharides, polysaccharides etc.32,33 For this fermentation, the microflora produces a vast number of enzymes like glucoronidase, xylosidase, arabinosidase, galactosidase, nitroreductase, azareducatase, deaminase, and urea dehydroxylase. 34 Because of the presence of the biodegradable enzymes only in the colon, the use of biodegradable polymers for colon-specific drug delivery seems to be a more site-specific approach as compared to other approaches.5 These polymers shield the drug from the environments of stomach and small intestine, and are able to deliver the drug to the colon. On reaching the colon, they undergo assimilation by micro-organism, or degradation by enzyme or break down of the polymer back bone leading to a subsequent reduction in their molecular weight and thereby loss of mechanical strength They are then unable to hold the drug entity any longer.

\section{Prodrug Approach for Drug Delivery to Colon}

Prodrug is a pharmacologically inactive derivative of a parent drug molecule that requires spontaneous or enzymatic transformation in vivo to release the active drug. For colonic delivery, the prodrug is designed to undergo minimal hydrolysis in the upper tracts of GIT, and undergo enzymatic hydrolysis in the colon there by releasing the active drug moiety from the drug carrier. Metabolism of azo compounds by intestinal bacteria is one of the most extensively studied bacterial metabolic process.41 A number of other linkages susceptible to bacterial hydrolysis specially in the colon have been prepared where the drug is attached to hydrophobic moieties like amino acids, glucoronic acids, glucose, glucose, cellulose etc. Limitations of the prodrug approach is that it is not a very versatile approach as its formulation depends upon the functional group available on the drug moiety for chemical linkage. Furthermore, prodrugs are new chemical entities, and need a lot of evaluation before being used as carriers. 


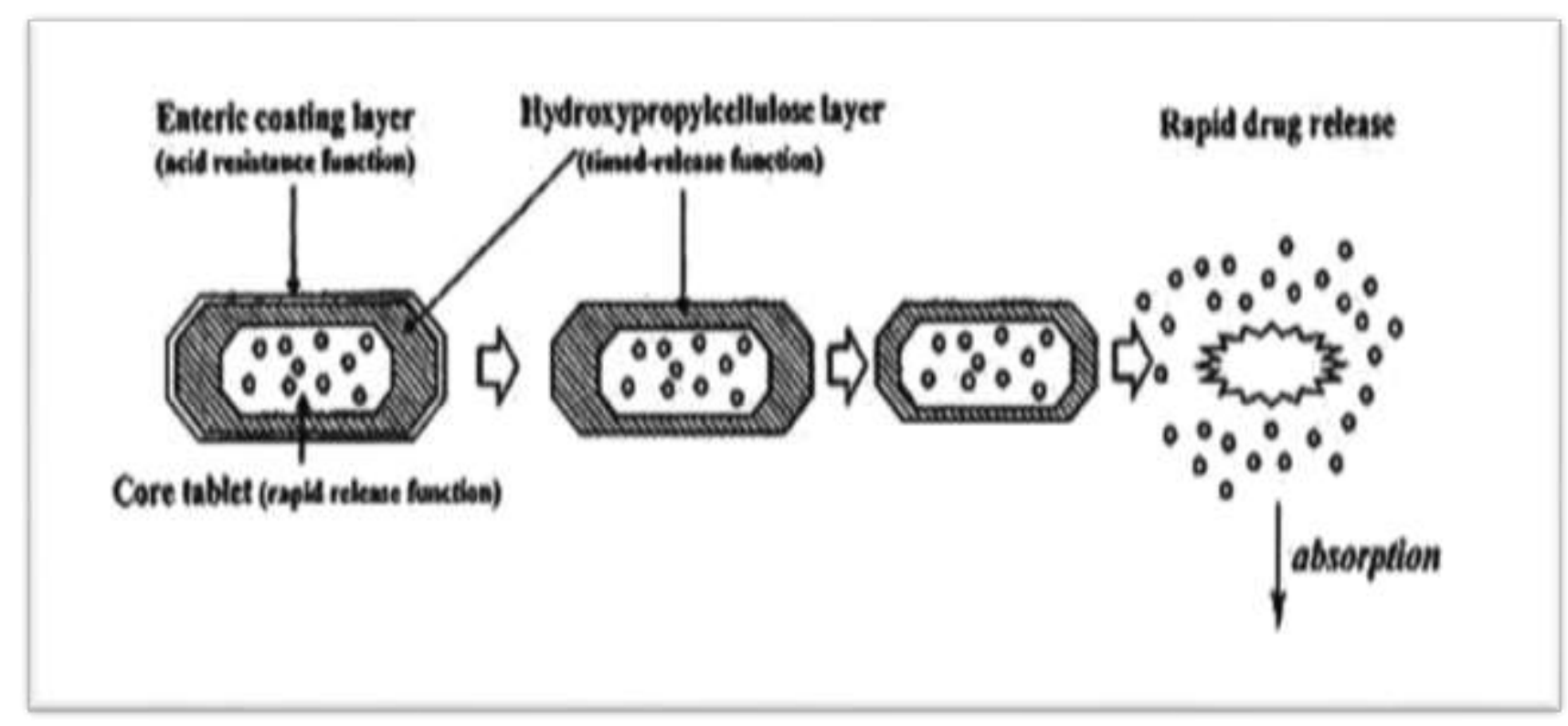

Figure 7: Design of enteric coated timed-release press coated tablet

Table 6: Enteric Polymers used in the development of Modified-Release Formulations for Colonic drug Delivery systems

\begin{tabular}{ll}
\hline Enteric Polymers & $\begin{array}{l}\text { Optimum pH } \\
\text { for dissolution }\end{array}$ \\
\hline Polyvinyl acetate phthalate (PVAP) & 5.0 \\
Cellulose acetate trimelitate (CAT) & 5.5 \\
Hydroxypropyl methylcellulose phthalate (HPMCP) & $\geq 5.5$ \\
Hydroxypropylmethylcellulose acetate succinate (HPMCAS) & $\geq 6.0$ \\
Methacrylie acid copolymer, Type C (Eudragit L100-55) & $\geq 6.0$ \\
Methacrylic acid copolymer dispersion (Eudragit L30D-55) & $\geq 5$ \\
Methacrylic acid copolymer, Tyep A & $\geq 6.0$ \\
(Eudragit@L-100 and Eudragist L12,5) & $\overline{6} .0$ \\
Cellulose acetate phthalate (CAP) (Aquateric) & $\geq 7.0$ \\
Methacrylic acid copolymer, Type B & - \\
(Eudragist S-100 and Eudragit S12,5) & $>7.0$ \\
Eudragit FS30D & 7.0 \\
Shellac (MarCoat 125 \&125N) & \\
\hline
\end{tabular}

Table 7: Microbially degradable polymers used for Colonic drug delivery system.

\begin{tabular}{ll}
\hline Class & Examples \\
\hline Disacharides & Lactose \\
Oligosaccharides & Maltose \\
& Cellobiose \\
& Cyclodextrins \\
& Lectulose \\
& Raffinose \\
& Stachyose \\
Polysaccharides & Alginates \\
& Amylose \\
& Arabinogalactan \\
& Arabinoxylan \\
& Cellulose \\
& Chitosan \\
& Chondroitin sulfate \\
\hline
\end{tabular}




\begin{tabular}{ll}
\hline Xextran \\
Galactomnam (guar gum, locust bean gun) \\
Inulin \\
Karaya gum (kadaya gum) \\
Laminarin \\
Pectins and pectates \\
Starch \\
Tragacanth gum \\
Xanthan gum \\
Xylan \\
\hline
\end{tabular}

\section{Newly Developed Approaches for CDD}

\section{Pressure Controlled Drug-Delivery Systems}

As a result of peristalsis, higher pressures are encountered in the colon than in the small intestine. Takaya et al. developed pressure controlled colon-delivery capsules prepared using ethylcellulose, which is insoluble in water.43 In such systems, drug release occurs following the disintegration of a water-insoluble polymer capsule because of pressure in the lumen of the colon. The thickness of the ethylcellulose membrane is the most important factor for the disintegration of the formulation. The system also appeared to depend on capsule size and density. Because of reabsorption of water from the colon, the viscosity of luminal content is higher in the colon than in the small intestine. It has therefore been concluded that drug dissolution in the colon could present a problem in relation to colon-specific oral drug delivery systems. In pressure controlled ethylcellulose single unit capsules the drug is in a liquid. Lag times of three to five hours in relation to drug absorption were noted when pressure-controlled capsules were administered to humans. ${ }^{27}$

\section{Novel Colon Targeted Delivery System (CODESTM)}

CODESTM is an unique CDDS technology that was designed to avoid the inherent problems associated with $\mathrm{pH}$ or time dependent systems.47,48 CODESTM is a combined approach of $\mathrm{pH}$ dependent and Microbially triggered CDDS. It has been developed by utilizing a unique mechanism involving lactulose, which acts as a trigger for site specific drug release in the colon, (Fig. 2). The system consists of a traditional tablet core containing lactulose, which is over coated with and acid soluble material, Eudragit E, and then subsequently over coated with an enteric material, Eudragit L. The premise of the technology is that the enteric coating protects the tablet while it is located in the stomach and then dissolves quickly following gastric emptying. The acid soluble material coating then protects the preparation as it passes through the alkaline $\mathrm{pH}$ of the small intestine.49 Once the tablet arrives in the colon, the bacteria enzymatically degrade the polysaccharide (lactulose) into organic acid. This lowers the $\mathrm{pH}$ surrounding the system sufficient to effect the dissolution of the acid soluble coating and subsequent drug release. ${ }^{27}$ 


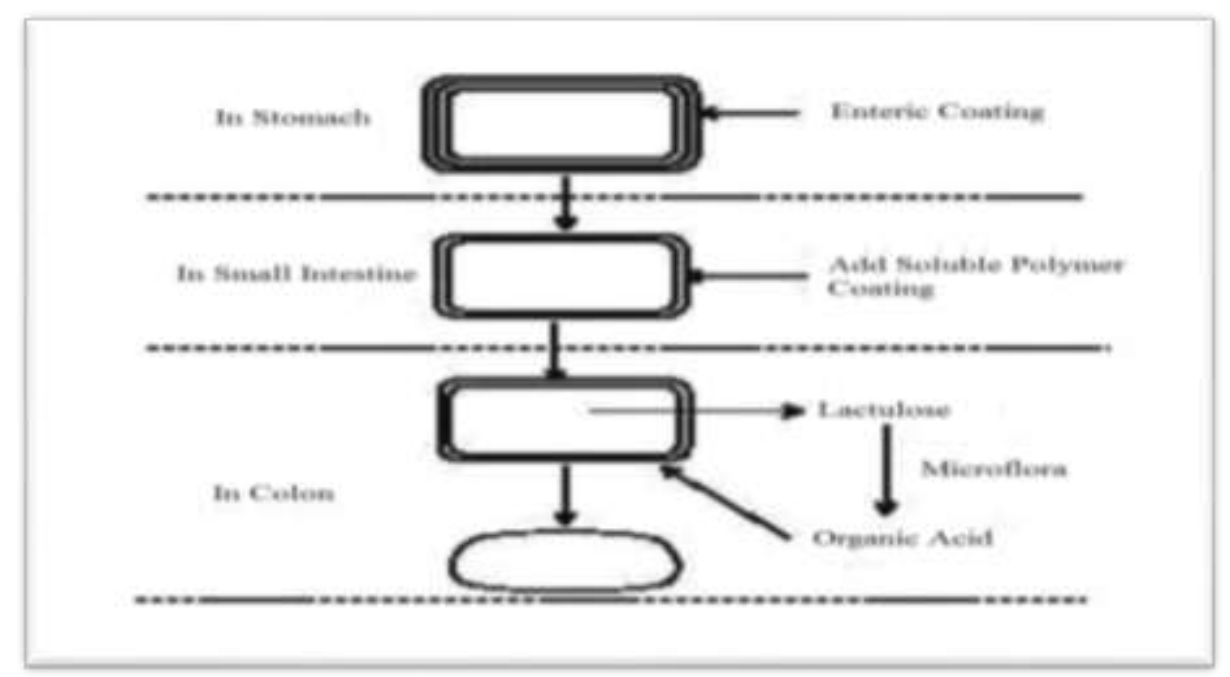

Figure 8: Schematics of the conceptual design of CODES ${ }^{\mathrm{TM}}$

\section{Osmotic Controlled Drug Delivery (ORDS-CT)}

The OROS-CT (Alza corporation) can be used to target the drug locally to the colon for the treatment of disease or to achieve systemic absorption that is otherwise unattainable.50 The OROS-CT system can be a single osmotic unit or may incorporate as many as 5-6 push-pull units, each $4 \mathrm{~mm}$ in diameter, encapsulated within a hard gelatin capsule, (Fig. 3).51 Each bilayer push pull unit contains an osmotic push layer and a drug layer, both surrounded by a semipermeable membrane. An orifice is drilled through the membrane next to the drug layer. Immediately after the OROS-CT is swallowed, the gelatin capsule containing the push-pull units dissolves. Because of its drug-impermeable enteric coating, each push-pull unit is prevented from absorbing water in the acidic aqueous environment of the stomach, and hence no drug is delivered. As the unit enters the small intestine, the coating dissolves in this higher $\mathrm{pH}$ environment ( $\mathrm{pH}>7$ ), water enters the unit, causing the osmotic push compartment to swell and concomitantly creates a flow able gel in the drug compartment. Swelling of the osmotic push compartment forces drug gel out of the orifice at a rate precisely controlled by the rate of water transport through the semipermeable membrane. For treating ulcerative colitis, each push pull unit is designed with a 3-4 h post gastric delay to prevent drug delivery in the small intestine. Drug release begins when the unit reaches the colon. OROS-CT units can maintain a constant release rate for up to 24 hours in the colon or can deliver drug over a period as short as four hours. Recently, new phase transited systems have come which promise to be a good tool for targeting drugs to the colon. ${ }^{27}$ 


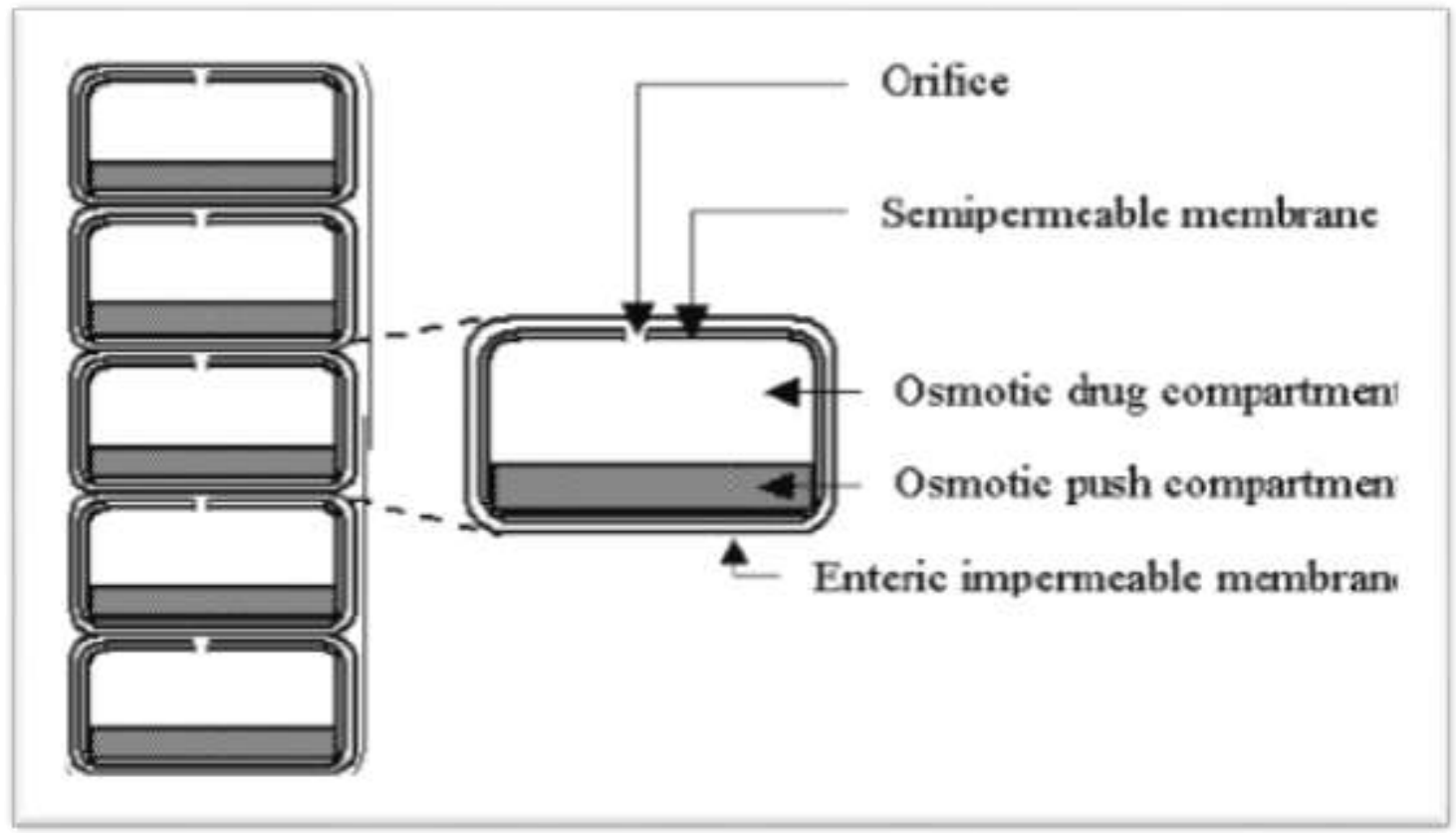

Figure 9: Cross-Section of the OROS-CT colon targeted drug delivery system

\section{Opportunities in colon targeted drug delivery}

- In the area of targeted delivery, the colonic region of the GI tract is the one that has been embraced by scientists and is being extensively investigated over the past two decades.

- Targeted delivery to the colon is being explored not only for local colonic pathologies, thus avoiding systemic effects of drugs or inconvenient and painful trans-colonic administration of drugs, but also for systemic delivery of drugs like proteins and peptides, which are other wise degraded and/or poorly absorbed in the stomach and small intestine but may be better absorbed from the more benign environment of the colon.

- This is also a potential site for the treatment of diseases sensitive to circadian rhythms such as asthma, angina and arthritis. Moreover, there is an urgent need for delivery of drugs to the colon that reported to be absorbable in the colon, such as steroids, which would increase efficiency and enable reduction of the required effective dose.

- The treatment of disorders of the large intestine, such as irritable bowel syndrome (IBS), colitis, Crohn's disease and other colon diseases, where it is necessary to attain a high concentration of the active agent, may be efficiently achieved by colon-specific delivery.

- The development of a dosage form that improves the oral absorption of peptide and protein drugs whose bioavailability is very low because of instability in the GI tract is one of the greatest challenges for oral peptide delivery.

- The bioavailability of protein drugs delivered at the colon site needs to be addressed. 
- More research is focused on the specificity of drug uptake at the colon site is necessary. Such studies would significant in advancing the cause of colon targeted drug delivery in future.

\section{Evaluation Of CDDS:}

The drug release in the colonic region from different CDDS is evaluated by different methods of in vitro and in vivo release studies, which show the success rate of different designs of colon drug delivery systems. Depending upon the method of preparation different evaluation methods are proposed. A successful colon specific drug delivery system is one of that remains intact in the physiological environment of stomach and small intestine, but releases the drug in the colon.

\section{In-vitro Evaluation:}

Different in vitro methods are used to evaluate the colonic drug delivery systems. In in-vitro studies the ability of the coats/carriers to remain intact in the physiological environment of the stomach \& small intestine is assessed by drug release studies in $0.1 \mathrm{~N} \mathrm{HCl}$ for two hours (mean gastric emptying time) and in $\mathrm{pH} 7.4$ phosphate buffer for three hours (mean small intestine transit time) using USP dissolution apparatus. In case of micro flora activated system dosage form, the release rate of drug is tested in vitro by incubating in a buffer medium in the presence of either enzymes (e.g. pectinase, dextranase) or rat/guinea pig / rabbit caecal contents. The amount of drug released at different time intervals during the incubation is estimated to find out the degradation of the carrier under study ${ }^{33}$

\section{In-vivo Evaluation:}

Like other controlled release delivery systems, the successful development of the CDDS is ultimately determined by its ability to achieve release in colonic region thus exerts the intended therapeutic effect. When the system design is concerned \& prototype formulation with acceptable in vitro characteristics is obtained, in vivo studies are usually conducted to evaluate the site specificity of drug release and to obtain relevant pharmacokinetic information of the delivery system. Although animal models have obvious advantages in assessing colon specific drug delivery systems, human subjects are increasingly utilized for evaluation of this type of delivery systems. The preferable animals to evaluate CDDS are rats, guinea pigs and dogs.$^{33}$

\section{CONCLUSION:}

The colonic region of the GIT has become an increasingly important site for drug delivery and absorption. CDDS offers therapeutic benefits to patients in both local and systemic treatment. Systems utilize natural materials that are degraded by colonic bacterial enzymes. Colon provides favorable factors and conditions for designing of delivery systems. High 
commercial viability. Increasing number of international patents and research work in this particular mode of drug delivery itself shows its potential for pharmaceutical market.

\section{REFERENCES:}

1. Glibert S Banker (ed.), Modern Pharmaceutics (4 ${ }^{\text {th }}$ edn), Marcel Dekker, New York, 2002, 527-584.

2. Abdul B, John B. Perspectives on Colonic Drug Delivery, Business Briefing, Pharmatech, 2003, 185-190.

3. Bajpai S K, Bajpai M, Dengree R. Chemically treated gelatin capsules for colontargeted drug delivery: a novel approach, J. Appl. Polym.Sci., 2003, 89, 2277-2282.

4. Edith mathiowitz (ed.). Encyclopedia of controlled drug delivery, John wiley and sons, Inc. Newyork, 2003, 698-726.

5. Sarasija S, Hota A. Colon-specific drug delivery systems, Indian journal of pharmaceutical sciences, 62(1), 2000, 1-8.

6. Chourasia M K, Jain S K. Pharmaceutical Approaches to Colon Targeted Drug Delivery, Journal of pharmaceutical sciences, 6(1), 2003, 33-66.

7. Colonic Delivery Formulations, Recent Patents on Drug Delivery and Formulation, 1(1), 2007, 55.

8. Hamman et al, Drug Target Insights, 2, 2007, 80.

9. Basit A W, Podczeck F, Newton J M. The use of formulation technology to assess regional gastrointestinal drug absorption in humans, Eur. J. Pharm. Sci., 21, 2004, 17989.

10. Stella V J, Charman W N, Naringrekar V H. Prodrugs, Inc: Do they have advantages in clinical practice? Drugs, 29, 1985, 455-473.

11. Higuchi T, Stella V (ed.). Prodrugs: an overview and definition. Inc: Prodrugs as Novel Drug Delivery Systems, ACS Symposium Series, Washington, DC: American Chemical Society, 1975, 1-115.

12. D'Acquisto F, May M J, Ghosh S. An emerging theme in anti-inflammatory therapies, Mol. Intervent., 2, 2002, 22-35.

13. Cawley D B, Simpson D L, Hershman H R. Biochimie, 68, 1981, 375-81.

14. Kopeck J, Kopeckova P, Brondsted H, Rath R, Lkesue K. Polymers for colon-specific drug delivery, Journal of controlled release, 19, 1992, 121-130.

15. Schacht E, Gevaert A, kenawy ER, Molly K Gelan J. Polymers for colon-specific drug delivery, Journal of controlled release, 39, 1996, 327-338. 
16. Ramprasad Y V, Krishnaiah Y S, Satyanarayana S. Studies of guar gum compressioncoated 5-aminosalicylic acid tablets for colon-specific drug delivery, Drug development and industrial pharmacy, 25(5), 1999, 651-657.

17. Sinha V R, Kumria R. Colonic drug delivery: prodrug approach, Pharmaceutical research, 224(1-2), 2001, 19-38.

18. Sinkula A A, Yalkowsky S H. Rationale for design of biologically reversible drug derivatives: prodrugs, J Pharm Sci., 64, 1975, 181-210.

19. Ardizzone S, Bollani S, Manzionna G, Bianchi Porro G. Inflammatory bowel disease approaching the 3rd millennium: pathogenesis and therapeutic implications. Eur $\mathbf{J}$ Gastroenterol Hepatol., 11(1), 1999, 27-32.

20. Ardizzone S, Porro G B. Comparative tolerability of therapies for ulcerative colitis, Drug Saf., 25(8), 2002, 561-82.

21. Ardizzone S, Porro G B. Inflammatory bowel disease: new insights into pathogenesis and treatment, J Intern Med., 252(6), 2002, 475-96.

22. Clemett D, Markham A. Colitis Foundation of America, Prolonged-release mesalazine: ulcerative colitis and Crohn's disease, Drugs, 59, 2000, 929-956.

23. Mahkam M, Doosite L. The relation between swelling properties and cross linking of hydrogels designed for colon- specific drug delivery, Drug delivery, 12(6), 2005, 343347.

24. Orienti L, Trere R, Zecchi V. Hydrogels formed by crosslinked polyvinylalcohol as colon-specific drug delivery systems, Drug development and industrial pharmacy, 27(8), 2001, 877-884.

25. Kinget R, Van-Den-Mooter G, Samyn C. Azopolymers for colon-specific drug delivery, Part 2. Influence of the type of azopolymer on degradation by intestinal microflora, International journal of Pharmaceutics, 93, 1993, 133-139.

26. Bronsted H, Hovgaard L, Simonsen L. Dextran hydrogels for colon-specific drug delivery, Part 3. In vitro and in vivo degradation, STP-Pharm-Sciences, 5(1), 1995, 6064.

27. Krishnaiah.Y S, Satyanarayana S. Inc: Advances in controlled and novel drug delivery: Colon-specific drug delivery systems, CBS Publishers and Distributors, New Delhi: India, 2001, 89-119.

28. Ramprasad Y V, Krishnaiah Y S, Satyanarayana S. In vitro evaluation of guar gum as a carrier for colon-specific drug delivery. Journal of controlled release, 59, 1998, 281287. 
29. Ramprasad Y V, Krishnaiah Y S, Satyanarayana S. Studies of guar gum compressioncoated 5-aminosalicylic acid tablets for colon-specific drug delivery, Drug development and industrial pharmacy, 25(5), 1999, 651-657.

30. Gliko Kabir L, Yagen B, Baluom M, Rubinstein A. Phosphated crosslinked guar gum for colon-specific drug delivery, Part 1. Preparation and physiological characterization, Journal of controlled release, 63, 2000, 121-127.

31. Gliko Kabir L, Yagen B, Baluom M, Rubinstein A. Phosphated crosslinked guar gum for colon-specific drug delivery, Part 2. In vitro and in vivo evaluation in the rat, Journal of controlled release, 63, 2000, 63:129-134.

32. Dautry-Varsat A. Biochimie, 68, 1986, 375-81.

33. Thacharodi D, Rap K P. Development and in vitro evaluation of chitosan- based drug delivery system, Biomaterials, 45, 1995, 145-8.

34. Nykänen P, Krogars K, Säkkinen M, Heinämäki J, JFrjenson H,Veski P, Marvola M. Organic acids as excipients in matrix granules for colon-specific drug delivery, Int. J. Pharm., 184, 1999, 251-261.

35. Krishnaiah Y S, Ramprasad Y V, Satyanarayana S, Seethadevi A, Nageswar Rao L Bhaskar P, Karthikeyan R R S. Guar gum as a carrier for colon specific delivery; Influence of metronidazole and tinidazole on in vitro release of albendazole from guar gum matrix tablets, Journal of pharmaceutical sciences, 4(3), 2001, 235-243.

36. Krishnaiah Y S, Kumar B D, Satyanarayana S, Karthikeyan R S. Studies on the development of oral colon targeted drug delivery systems for celecoxib in the prevention of colorectal cancer. Journal of drug targeting. 2002; 10(3):247-254.

37. Krishnaiah Y S, Bhaskar Reddy P R, Satyanarayana S, Karthikeyan R S. Studies on the development of oral colon targeted drug delivery systems for metronidazole in the treatment of amoebiasis, International journal of pharmaceutics, 236(1-2), 2002, 43-55.

38. Sinha V R, Kumria R. Microbially triggered drug delivery to the colon, European journal of pharmaceutical sciences, 18(1), 2003, 3-18.

39. Bankar J A. Matrix tablets, Inc: The theory and practice of industrial pharmacy ( $\left.3^{\text {rd }} \mathrm{edn}\right)$, Verghese publishing House, Bombay, 1987, 453-455.

40. Breimer D D. Future challenges for drug delivery, J Control Rel 62, 1999, 3-6.

41. Basit A, Bloor J. Perspectives on colonic drug delivery, Business Briefing, Pharmatech., 2003, 185-190.

42. Langer R. Drug delivery and targeting, Nature, 392, 1998, 5-10.

43. Kost J, Langer R. Responsive polymeric delivery systems, Adv Drug Deliv Rev., 46, 2001, 125-148. 
44. Colonic Delivery Formulations, Recent Patents on Drug Delivery and Formulation, 1(1), 2007, 57.

45. Nykänen P, Lempää S, Aaltonen M L, JFrjenson H, Veski P, Marvola M. Citric acid as excipient in multiple-unit enteric coated tablets for targeting drugs on the colon. Int. J. Pharm., 229, 2001, 155-162.

46. Colonic Delivery Formulations, Recent Patents on Drug Delivery and Formulation, 1(1), 2007, 59.

47. Basit A, Bloor J. Perspectives on colonic drug delivery, Business Briefing, Pharmatech., 2003, 185-190.

48. Davis S S, Robertson C, Wilding IR. Gastrointestinal transit of a multiparticulate tablet formulation in patients with active ulcerative colitis, Int J Pharm., 68, 1991, 199-204.

49. Panchagnula R. Transdermal delivery of drugs, Indian J Pharmacol., 29, 1997, 140-56.

50. Rao P R, Diwan P V. Formulation and in vitro evaluation of polymeric films of diltiazem hydrochloride and indomethacin for transdermal administration, Drug Dev Indian Pharmac., 24, 1998, 327-36.

51. Nykänen P, Krogars K, Säkkinen M, Heinämäki J, JFrjenson H, Veski P, Marvola M. Organic acids as excipients in matrix granules for colon-specific drug delivery. Int. J. Pharm., 184, 1999, 251-261.

52. Rao P R, Diwan P V. Formulation and in vitro evaluation of polymeric films, Drug Dev Indian Pharmac., 24, 1998, 327-36.

53. Thacharodi D, Rap K P. Development and in vitro evaluation of chitosan- based drug delivery system, Biomaterials, 16, 1995, 145-8.

54. Ariese F, Ernst WHO, Sijm DTHM. Natural and synthetic organic compounds in the environment — a symposium report, Environ Toxicol Pharmacol., 10, 2001, 65-80.

55. Aura A M, O’Leary K A, Williamson G, Ojala M, Bailey M, Puupponen Pimia R. Quercetin derivatives are deconjugated and converted to hydroxyphenylacetic acids but not methylated by human fecal flora in vitro, J Agr Food Chem., 50, 2002, 1725-1730.

56. Breimer DD. Future challenges for drug delivery, J Control Rel., 62, 1999, 3-6.

57. J M Hebden, C G Wilson, R C Spiller, P J Gilchrist, E Blackshaw. Colon assessed time release delivery system", Pharmaceutical Research, 16, 1999, 1,087-1,092.

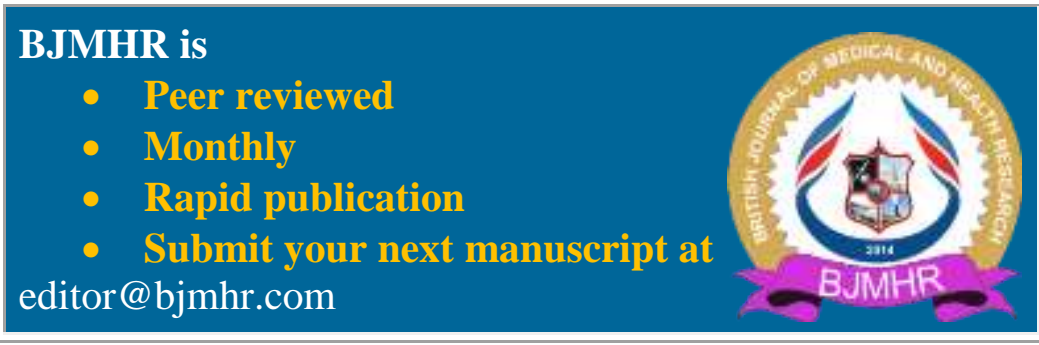

